\title{
Pituitary tumours: findings from whole genome analyses
}

\author{
W E Farrell
}

Human Disease and Genomics Group, Institute of Science and Technology in Medicine, School of Medicine, Keele University, Stoke on Trent, Staffordshire ST4 7QB, UK

(Requests for offprints should be addressed to W E Farrell; Email: w.e.farrell@keele.ac.uk)

\begin{abstract}
Pituitary tumours are common intracranial neoplasms that cause significant morbidity through mass effects and/or the inappropriate secretion of pituitary hormones. Despite a considerable literature detailing potential pathogenic changes in these tumours, their aetiology remains largely unresolved. Recent studies have employed genome-wide profiling towards the identification of novel genes and pathways that are inappropriately expressed or regulated in this tumour type. The techniques employed vary in their complexity and interpretation; however, many of the findings from these types of studies have identified novel genes with potential and, in some cases, proven roles in pituitary tumorigenesis. These studies include comparative genomic hybridization, whole genome-wide allelotyping and methodologies for identification of novel genes associated with epigenetic silencing. In addition, differential display methodologies have been instrumental in the identification of transcripts inappropriately expressed including, pituitary tumour transforming gene, growth arrest and DNA damage-inducible protein (GADD) $45 \gamma$ and a maternal expressed gene 3 isoform, which in some cases have proven roles in pituitary tumorigenesis. Although few studies of whole genome transcript analysis, as determined by microarray or gene-chip technologies, are reported, these studies of human pituitary, in some cases combined with proteomics, are yielding useful data. In addition, these types of investigation have been applied to several animal models of pituitary tumorigenesis, and in these cases novel genes are highlighted as showing significant change. The identification of the initiating events responsible for the transformation of a normal pituitary cell into one with unrestrained proliferative capacity has so far eluded us. No doubt, these new technologies allowing an essentially unbiased genome-wide analysis, perhaps in combination with animal models that display a preceding hyperplasia, will allow us to identify genes critical to tumour evolution and progression.
\end{abstract}

Endocrine-Related Cancer (2006) 13 707-716

\section{Pathogenesis of pituitary tumours}

\section{Pituitary adenomas}

Pituitary adenomas are common intracranial neoplasms, comprising $10-15 \%$ of diagnosed brain tumours (Kovacs \& Hovarth 1987). Tumours may arise from any of the five differentiated cell types within this gland, and reflecting their cellular origin frequently synthesize and secrete their respective hormone(s) (Asa \& Ezzat 2002, Melmed 2003). In these cases, excess hormone secretion, for example, prolactin, growth hormone $(\mathrm{GH})$ and adrenocorticotrophic hormone (ACTH), are responsible for severe clinical syndromes that can be lethal. In addition, a significant percentage of tumours, typically macroadenomas, are classified as clinically non-functioning and do not cause syndromes of hormone excess. Irrespective of hormonal status, tumours show a spectrum of growth characteristics and rapidly growing tumours give rise to symptoms of intracranial mass including headache, loss of normal anterior pituitary hormone production (through compressive effects) and visual field defects (Asa \& Ezzat 2002, Melmed 2003). Pituitary tumours rarely metastasize; however, a significant proportion show invasive and or recurrent growth characteristics (Pernicone et al. 1997, Heaney \& Melmed 2004). 


\section{Pituitary tumour clonality}

The near-invariable finding of monoclonality in this tumour type supports the view that a somatic cell defect represents the primary initiating event (Alexander et al. 1990, Herman et al. 1990). However, clonal outgrowth is most likely facilitated by hypothalamic and pituitaryderived growth factors (Asa \& Ezzat 2002, 2005). Although the majority of the pituitary tumours are sporadic, they are also found as components of several familial syndromes, including multiple endocrine neoplasia type 1, Carney complex and McCuneAlbright syndrome (reviewed by Farrell 2005).

\section{Pathogenic changes implicated in pituitary tumourigenesis}

Considerable literature details the potential pathogenic changes in sporadic pituitary tumours that include hormones, growth factors, receptors, associated signal transduction pathways and cell-cycle regulators. A detailed consideration and analysis of these changes has been the subject of several recent reviews (Asa \& Ezzat 2002, 2005, Melmed 2003, Heaney \& Melmed 2004). However, despite our understanding of the aberrations that characterize this tumour type, their aetiology remains largely unresolved. Thus, it is difficult to determine if an identified change represents a primary (initiating) pathogenic event, responsible for cell transformation, or represents a change that promotes or facilitates tumour progression or, conversely, simply reflect tumour-associated epiphenomenon. In tumours, such as colon cancers, it is possible to delineate molecular aberrations associated with each stage of progression; however, pituitary tumours are not usually associated with preceding hyperplasia, noninvasive tumours do not necessarily progress to invasive adenoma and metastatic outgrowth is exceedingly rare (Asa \& Ezzat 2002, Melmed 2003). In response to these challenges, recent studies have employed genome-wide approaches toward the identification of novel genes and/or pathways with potential, and in some cases proven roles in pituitary tumorigenesis. The primary focus of this review will be on the recent findings derived from whole genome analyses studies, and the principal techniques employed are detailed in Table 1.

\section{Loss of heterozygosity (LOH) in sporadic pituitary tumours}

The majority of studies employing $\mathrm{LOH}$ analyses to identify tumour suppressor gene loci in sporadic pituitary tumours utilize candidate gene approaches. For some of the loci identified, an increased frequency of $\mathrm{LOH}$ (at one or more loci) is apparent in invasive tumours and pituitary carcinomas relative to their non-invasive counterparts (Bates et al. 1997). The subsequent identification of the MEN1 gene, which maps to one of the regions identified (11q13), led to its characterization in sporadic pituitary tumours. Disappointingly, these studies largely discounted a significant role for this gene in sporadic pituitary tumours (Asa \& Ezzat 2002, Melmed 2003). Studies of the $R B 1$ gene that maps to $13 \mathrm{q} 14$, a region also identified as harbouring frequent $\mathrm{LOH}$, also reached similar conclusions. However, the findings relating to the $R B 1$ gene and its protein product may reflect the tumour subtypes investigated and/or mechanisms associated with inactivation and they will be reviewed in a subsequent section.

\section{Whole genome cytogenetic alterations}

Disruption in cell-cycle checkpoints leads to chromosomal instability and is a hallmark of tumorigenesis. Pituitary tumours are no exception and approximately half are reported as grossly aneuploid (Levy \& Lightman 2003). A principal technique employed to define these changes, and that permits the simultaneous examination of all autosomes, is comparative genomic hybridization. This technique allows gross chromosomal changes (gains and losses) and ploidy to be determined in a single experiment. These studies have

Table 1 Whole genome analysis of human pituitary tumours

Technique

Comparative genomic hybridization, $\mathrm{CGH}$

Primer extension pre-amplification, PEP

Genome-wide allelotyping

Differential mRNA display

cDNA-representational difference analysis, RDA

Methylation sensitive arbitrarily primed PCR (Ms-AP-PCR)

Microarray analysis (cDNA and oligonucleotide)

\section{Gene-transcript or genomic region identified}

Ploidy, gross chromosomal gains, losses and translocations

Essentially unbiased amplification of DNA prior to genome-wide allelotyping $\mathrm{LOH}$

Discrete genomic 'hotspots' identified displaying $\mathrm{LOH}$

PTTG, Noggin/BMP4

GADD45 $\gamma$, MEG3a

Pituitary tumour apoptosis Gene PTAG

Multiple transcripts 
examined all the major pituitary tumour subtypes; however, the number of tumours examined is limited (Tanaka et al. 1997, Daniely et al. 1998, Harada et al. 1999, Hui et al. 1999, Metzger et al. 1999, Finelli et al. 2000, Fan et al. 2001, Rickert et al. 2001, Trautmann et al. 2001). Perhaps reflecting this limitation, these studies reached different conclusions with respect to gains and losses. For example, the combined data from these studies describe losses on chromosomes 1, 2, 3, 9, $10,11,13,15,16,18$ and 22. Although these studies reached similar conclusions for losses on the long arms of chromosome 1,2,11, 13 and 15, this was not the case for the losses of the other regions. In general, these studies show that chromosomal aberrations are more frequent in functional adenomas than their nonfunctional counterparts, and are more common in invasive and recurrent tumours than their benign counterparts. A technical limitation of this technique, with respect to identification of chromosomal losses, is that it is limited to analysis and identification of large regions of chromosomal deletion, whereas microdeletions may remain undetected.

\section{Genome-wide microsatellite analysis}

A genome-wide microsatellite analysis for $\mathrm{LOH}$ was made possible through essentially unbiased whole genome amplification (Simpson et al. 2003). Across the genome, the analysis identified discrete regions where LOH exceeded the frequency that accounts for (tumour-associated) random allelic loss. The study also identified regions and specific microsatellite markers that showed an increase in the frequency of $\mathrm{LOH}$ in invasive tumours relative to their non-invasive counterpart (Fig. 1). Microsatellite markers identified in this genome-wide analysis were subsequently employed to determine their value as predictive markers of tumour recurrence (Buch et al. 2004). This retrospective study identified particular loci in the initial tumour specimens that were indeed predictive of recurrent growth (Buch et al. 2004). It will be important to employ these markers in a prospective study to determine if this type of analysis is truly predictive of subsequent tumour behaviour. In addition, the whole-genome analysis identifies chromosomal hot-spots for the location of novel tumour suppressor gene (TSG).

\section{Differential display techniques}

\section{Pituitary tumour transforming gene (PTTG)}

The isolation and characterization of the PTTGl gene transcript from a rat pituitary tumour cell line
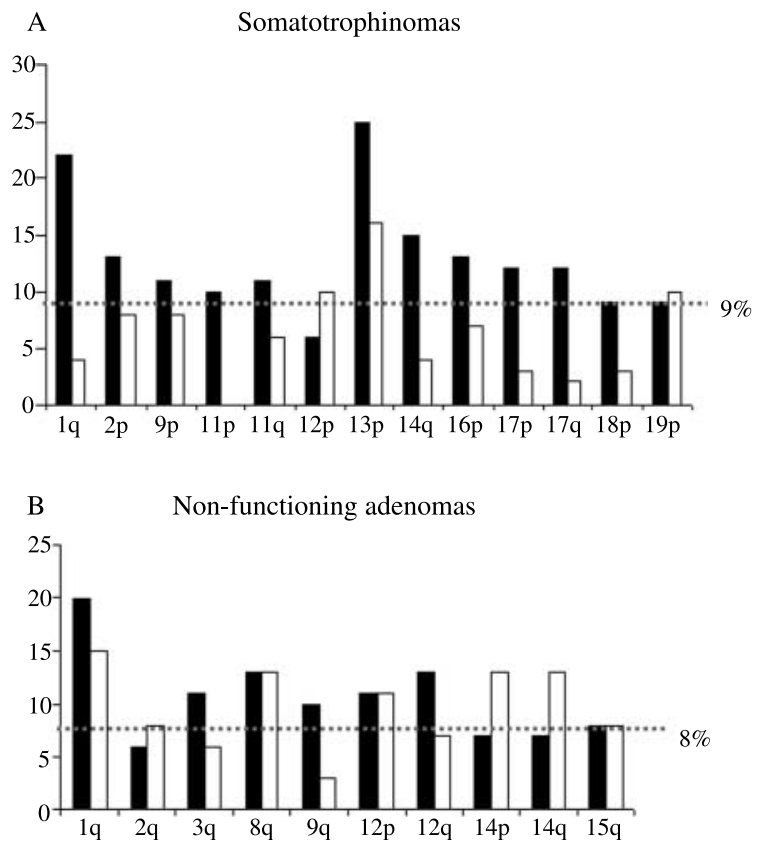

Figure 1 Mean frequency of loss of heterozygosity (LOH) at each chromosomal arm in invasive and non-invasive somatotrophinomas (A) and non-functioning adenomas (B). An LOH frequency in somatotrophinomas of 9 and $8 \%$ in non-functioning adenomas (mean percentage LOH plus one s.D.) was considered significant. The dashed line indicates the level of significance representing the $99 \%$ upper confidence limit for the overall rate of random chromosomal loss. Only chromosomal arms for which LOH equalled or exceeded this level of significance relative to either their non-invasive or invasive tumour counterparts are shown. Filled and unfilled bars represent invasive and non-invasive tumours respectively. Simpson D, Bicknell E J, Buch H N, Cutty S J, Clayton R N and Farrell W E 2003. Genome-wide amplification and allelotyping of sporadic pituitary adenomas identify novel regions of genetic loss Genes, Chromosomes \& Cancer 37 225-236. Reproduced with permission. Copyright (2003) Wiley-Liss, Inc.

represented the first report in this tumour type employing mRNA differential display (Pei \& Melmed 1997). $P T T G$ is overexpressed in human pituitary tumours, and increased expression correlates with tumour invasiveness (Zhang et al. 1999). The in vitro transforming properties of PTTG, a human securin, were first demonstrated in NIH3T3 cells (reviewed in Melmed 2003) and its in vivo role in tumour development has been investigated in different animal models. These studies show, in experimentally induced rat pituitary adenomas, that tumour growth is blocked through expression of a dominant negative form of PTTG (Horwitz et al. 2003), and that PTTG deletion protects, or significantly delays, pituitary tumour development in $\mathrm{Rb}^{+/-}$mice (Chesnokova et al. 2005). Targeted expression of PTTG1 to the mouse pituitary, under the control of the $\alpha$-GSU (glycoprotein 
hormone alpha subunit) promoter, was employed to more directly assess the role of PTTG in tumorigenesis (Abbud et al. 2005). These experiments showed that male transgenic animals have larger and irregularly shaped pituitaries. In some animals, PTTG expression was associated with focal pituitary hyperplasia and in some cases adenoma. The evidence for adenoma formation, that comprised luteinizing hormone (LH)or GH- or thyroid-stimulating hormone (TSH)-cell adenoma, includes loss of the reticulin network, a ribbon like pattern of adenoma cells and extensive pituitary vacuolization.

\section{Bone morphogenetic protein 4 and noggin}

A more recent study, employing mRNA differential display, identified decreased expression of the bone morphogenetic protein (BMP) inhibitor noggin in prolactinomas from D2-receptor-deficient mice (Paez-Pereda et al. 2003). In these tumours, confined to female mice, the decrease in noggin was associated with increased expression of BMP-4. Human prolactinomas, but not other pituitary tumour subtypes, showed increased expression of BMP-4 as determined by western blot analysis. Employing $c-m y c$ as a surrogate marker for cell proliferation, the study also showed that BMP-4 selectively stimulates, and noggin inhibits, cell proliferation in human prolactinomas, but not in other pituitary tumour subtypes. The same study also showed that enforced expression of noggin or a dominant negative form of Smad4 (a BMP-4 signal cotransducer) in $\mathrm{GH} 3$ cells reduced tumourigenicity in nude mice. A follow-on study by this group shows that most BMP-4 immunopositivity in normal pituitary is confined to somatotroph and corticotroph, but not lactotroph cell populations (Giacommini et al. 2006). In addition, this study shows that BMP-4 is expressed at low, but variable, levels in human corticotroph tumours associated with Cushing's disease. In contradistinction to their earlier findings in cells of the somatolactotroph lineage (GH3 cells), enforced expression of BMP-4 in AtT20 in the corticotroph cell lineage inhibited proliferation in vitro and blocked tumour cell growth in vivo. These findings are thought to reflect the differences in cell lineage (corticotrophs vs somatolactotrophs), where BMP-4 either inhibits or stimulates cell growth respectively. In agreement with previously published data, retinoic acid inhibited AtT20 cell proliferation and in vivo tumour cell growth (Paez-Pereda et al. 2001). Interestingly, this subsequent study shows that retinoic acid induces BMP4 transcription and translation. Although not addressed in these studies, it will be of interest to determine the consequence of noggin deficiency and targeted BMP-4 expression in appropriate mouse models.

\section{GADD45 $\gamma$}

Zhang and colleagues (2002) used a similar genomewide approach, in this case cDNA representational differential display, to isolate novel candidate genes subject to differential expression in human pituitary tumours. Their study differed from those described so far in that the primary source of RNA was normal human pituitary and clinically non-functioning pituitary tumours. They identified $G A D D 45 \gamma$, a growth arrest and DNA damage inducible gene, as significantly underexpressed in the majority of pituitary tumours investigated. The growth suppressive properties of this gene, in a pituitary context, were investigated in vitro; transfection of GADD45 $\gamma$ significantly reduced tumour cell line proliferation as determined by colony-forming efficiency (CFE) assays. Similar conclusions, with respect to reduced expression of $G A D D 45 \gamma$, in a significant proportion of pituitary tumours were reached in an independent study (Bahar et al. 2004b). This study also investigated the mechanisms responsible for or associated with loss of transcript expression and showed that loss of $G A D D 45 \gamma$ expression was significantly associated with methylation of this gene $\mathrm{CpG}$ island. Interestingly, the murine homologue of this gene is not expressed in the mouse pituitary cell line AtT20 and the $\mathrm{CpG}$ island associated with murine $G A D D 45 \gamma$ is also heavily methylated. Treatment of these cells with the demethylating agent 5-Aza 2'-deoxycytodine resulted in robust re-expression of this gene (Bahar et al. 2004b). It is important to note that these findings do not show that methylation per se is responsible for gene silencing; however, they do show this change is causal in maintaining the silent epigenetic state. More recent studies from our laboratory have shown, in AtT20 cells, that methylation of the $\mathrm{CpG}$ island associated with the GADD45 $\gamma$ gene is present in late passage, but absent in earlier passage cells (Bahar A and Farrell WE, unpublished observation).

\section{MEG3}

MEG3, an imprinted, maternally expressed gene of unknown function, was initially identified as underexpressed in non-functioning pituitary tumours in the same study that first identified and investigated the role of $G A D D 45 \gamma$ in this tumour type (Zhang et al. 2002). In a subsequent study, the same group identified expression of an isoform of MEG3, the cDNA of which, they termed MEG3a, which is expressed in 
normal human anterior lobe pituitary cells including gonadotrophs, but not expressed in most non-functioning tumours or somatotrophinomas (Zhang et al. 2003). The growth-suppressive properties of this isoform were investigated in different human tumour cell lines, including HeLa, MCF-7 and H4. Ectopic expression of MEG3a in these cell lines led to a significant decrease in CFE and the growth rate of HeLa cells as determined by cell proliferation experiments (Fig. 2). Additional investigations, as these authors point out, using an animal model will be critical to address whether the loss of MEG3 gene function is directly associated with tumour development.

To investigate the mechanisms associated with loss of $M E G 3$ in non-functioning pituitary tumours, Zhao and colleagues (2005) undertook a genetic and epigenetic analysis of this gene. No genomic abnormality, as determined by $\mathrm{LOH}$ analysis or direct sequencing, was detected in tumours that failed to express the MEG3 transcript. Employing sodium bisulphite sequencing to determine the methylation status of the putative MEG3 promoter region, two CpGrich regions in the $5^{\prime}$ sequences of this single copy gene were identified as hypermethylated in non-expressing tumours. Sequencing of individual molecules by this technique revealed a methylation profile indicative of imprinting in normal pituitary. Furthermore, the functional importance of these regions was demonstrated in transient transfection reporter assays. Gene silencing was effectively reversed in cell lines treated with a demethylating agent, supporting a role for this epigenetic change in gene silencing.

\section{Methylation associated gene silencing in pituitary tumorigenesis}

The role of inappropriate methylation, histone deacetylation and histone modification in tumour-associated gene silencing has been subject to recent review (Jones $\&$ Baylin 2002). The first gene subject to detailed investigation for epigenetic change in sporadic pituitary tumours was the tumour suppressor gene CDKN2A (commonly referred to as p16). Numerous studies have shown methylation of this gene $\mathrm{CpG}$ island in pituitary tumours, and when studied show an association with gene silencing (Farrell 2005). Methylation appears to be an early change in pituitary tumorigenesis (Simpson et al. 2004) and enforced expression of this gene in pituitary cell lines inhibits cell proliferation (Frost et al. 1999) consistent with its role as a cell-cycle regulator. Subsequent studies, also employing candidate gene approaches, have described methylation-mediated gene silencing in other
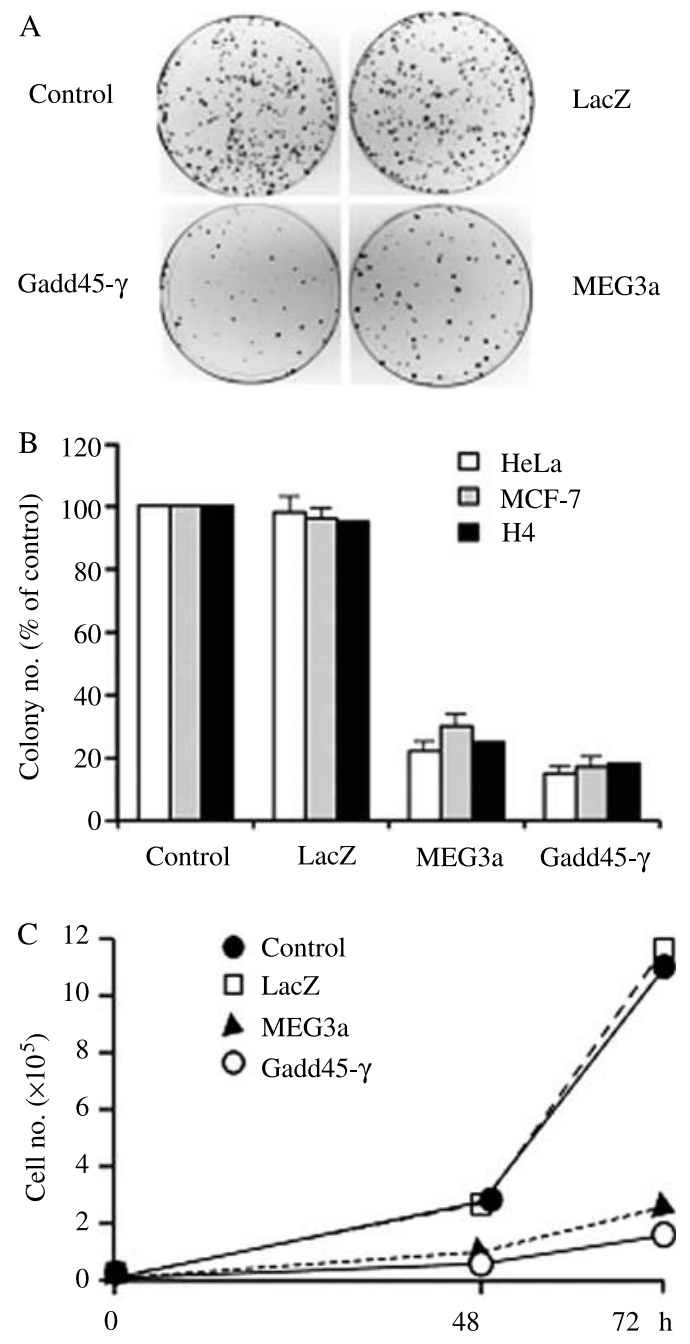

Figure 2 MEG3a suppresses tumour cell growth. (A) H4 cells were transfected with the blank vector $\mathrm{pCl}-$ neo (control) or expression vector for $L a c Z, M E G 3$ or GADD45y. After 2 weeks of neomycin selection, the plates were fixed and stained with crystal violet solution. (B) Viable colonies of HeLa, MCF-7 and $\mathrm{H} 4$ cells in similar experiments were counted and normalized to control. The data are represented as mean \pm s.D. for counts from at least three independent experiments. (C) HeLa cells were co-transfected with expression construct $\mathrm{pCl}-\mathrm{neo}, \mathrm{pCl}-$ neo-LacZ, pCl-neo-MEG3a or pCl-neo-GADD45 $\gamma$, along with the plasmid pMACS $\mathrm{K}^{\mathrm{k}}$.II for selection. After purification with a magnetic column, the growth rate for the transfected cells was determined by direct counting. Zhang X, Zhou Y, Mehta KR, Danila DC, Scolavino S, Johnson SR \& Klibanski A 2003. A pituitary derived MEG3 isoform functions as a growth suppressor in tumor cells. Journal of Clinical Endocrinology and Metabolism 88 5119-5126. Reproduced with permission. Copyright 2003, The Endocrine Society.

cell-cycle regulators, including the $R B 1$ gene and also in genes with roles in apoptosis, invasion and metastasis (death-associated protein kinase and Galectin 3). The role of these genes in pituitary tumorigenesis has been subject to recent review (Farrell 2005). 


\section{Identification of genome-wide differential methylation}

Methylation-associated gene silencing of $G A D D 45 \gamma$ and MEG3 promoter sequences represent the first, albeit indirect, genome-wide approach employed in the identification of epigenetic change in pituitary tumorigenesis. Bahar and co-workers (2004a) adopted a more direct approach through analysis of DNA sequences that were inappropriately methylated in pituitary tumours relative to normal gland. The technique, methylation-sensitive arbitrarily primed PCR (Gonzalgo et al. 1997), identified DNA sequences, which were differentially methylated in pituitary tumours relative to the normal gland. One of the sequences identified corresponded to an open reading frame on chromosome 22 (C22orf3) of unknown function. The majority of pituitary tumours, irrespective of subtype, either did not express or expressed low levels of this transcript relative to normal gland. Sodium bisulphite sequencing of individual adenomas revealed dense, but heterogeneous methylation that was associated with loss of transcript expression; however, it was confined to approximately $20 \%$ of adenomas that failed to express this gene. These findings suggest that mechanisms other than, or in addition to, methylation as responsible for loss of transcript expression. The functional consequences, contingent on re-expression of this novel sequence, were examined in the pituitary tumour cell line AtT20. Induced expression had no effect on proliferation or cellular viability relative to wild-type cells. To investigate a possible role in apoptotic pathways, cells were challenged with bromocriptine, which was shown previously to elicit an apoptotic response in this cell line (Yin et al. 1994, 1999). In dose-response experiments, expression of the novel sequence significantly augmented an apoptotic response relative to wild-type cells. Further studies showed that apoptosis was mediated through a preceding caspase-activating pathway. The terminal stages of apoptosis, as determined by terminal deoxynucleotidyl transferase biotin-dUTP nick end labelling (TUNEL) labelling, also showed an increase in the number of apoptotic cells relative to cells harbouring an empty vector control. Thus, each of these end-points shows that this gene significantly augments a drug-induced apoptotic response. On this basis, we assigned the gene the acronym PTAG, pituitary tumour apoptosis gene. The ability of cells showing reduced expression of PTAG to evade or show a blunted apoptotic response may underlie oncogenic transformation in the pituitary and perhaps other tumour types.
In summary, methylation-mediated or associated gene silencing represents a fundamental aspect of tumorigenesis in multiple tumour types (Jones \& Baylin 2002). Both candidate and novel gene approaches have provided new insight with regard to this change in pituitary tumours. Within the list of genes already identified, some show pituitary tumour subtype specificity, while others segregate with tumours that show invasive growth characteristics (reviewed by Farrell 2005). The specificity of this change with respect to tumour subtypes and growth characteristics together with functional consequences contingent on expression would suggest that this change does not simply reflect a tumour-associated epiphenomenon. As more data emerge, it will be possible to generate methylation profiles that provide a more detailed characterization of tumour subtypes and are perhaps predictive of growth characteristics. In contrast to gene loss, associated with deletion or mutation, methylation represents a potentially reversible change and thus offers exciting possibilities for pharmacological interventions strategies in tumour management.

\section{Genome-wide microarray analysis of pituitary tumours}

Microarray analysis has the advantage of permitting simultaneous analysis of thousands of genes at the level of transcript expression in a single experiment. Although few studies have applied this technology to the study of human pituitary tumours, the potential of this genome, or perhaps more accurately 'transcriptome' (Hu et al. 2005), wide parallel analysis toward identification of genes that underlie tumorigenesis, which are prognostic markers or therapeutic targets, cannot be overestimated. Technically, these experiments are relatively straightforward to perform; however, experimental design, inherent tumour cell heterogeneity and the complexity of data analysis represent significant challenges with respect to accurate interpretation (Fathallah-Shaykh 2005). In carefully designed studies that take into account of these multiple variables, these experiments generate reliable data pertaining to genome-wide transcript expression (Draghici et al. 2006).

\section{Gene expression profiling and human pituitary tumours}

To date, there are three published studies of gene expression profiling, as determined by microarray analysis of human pituitary tumours (Evans et al. 2001, Moreno et al. 2005, Morris et al. 2005). A further 
three studies have applied this analysis to the study of rodent pituitary adenomas (Goidin et al. 2000, Wood et al. 2002, Mohammed et al. 2004b). In the three studies of human pituitary tumours, expression profiles were compared with that obtained from normal pituitary gland. These studies identified multiple transcripts as being significantly over- or underexpressed in tumours relative to normal pituitary and for selected transcripts were validated by quantitative RT-PCR. However, the conclusions reached should, at present, be interpreted with caution since the pituitary comprises an admix of different cell types, whereas the tumours comprise an expanded population of one major cell type. Thus, at this time, these data must be regarded as preliminary, requiring further validation where expression is compared between the tumour subtype and its specific normal cellular counterpart.

\section{Gene expression profiling and animal models}

Three studies of pituitary tumours in animal models have exploited whole genome microarray analysis (Goidin et al. 2000, Wood et al. 2002, Mohammed et al. 2004b). In comparison to gene expression profiling of human tumours, these studies, by their nature, are better controlled and have yielded useful data. Goidin and colleagues (2000) used microarrays, comprising 588 known gene cDNAs to identify gene expression profiles linked to the ageing-associated occurrence of spontaneous pituitary adenoma in a rat animal model. Expression profiles from 3-month-old rats and tumour-bearing 20-28-month-old rats identified expression of 79 genes. In older, tumour-bearing animals, 28 genes were expressed at higher levels, whereas in younger animals 15 genes were expressed at higher levels. Expression levels of selected genes were validated by semi-quantitative RT-PCR. The largest differences were found for expression of galanin and glutathione S-transferase in old and young rats respectively.

Wood et al. (2002) characterized early changes in gene expression that preceded thyroid hormone (TH)induced involution of a TSH-secreting tumour grown in a hypothyroid host. Of the 1176 genes on the array, seven were upregulated and 40 downregulated subsequent to $\mathrm{TH}$ treatment. Observed changes in expression levels were validated by Northern blot analysis. Transcript levels for the cell-cycle regulators, cyclin-dependent kinase 2, cyclin A and p57 were decreased, whereas p15, a tumour suppressor, was induced by $\mathrm{TH}$ treatment. Several known, THresponsive genes, including chromogranin $\mathrm{B}$ and $\mathrm{C}$, inhibin, proconvertase 1 , brain-derived neurotrophic factor, its receptor trkB and the receptor for thyrotrophin-releasing hormone showed decreased expression following treatment. Interestingly, p19ARF was dramatically induced by TH treatment and, although this protein can stabilize p53 by sequestering $\mathrm{mdm} 2$, no increase in $\mathrm{p} 53$ protein was apparent. Identification of these early changes in gene expression that precedes $\mathrm{TH}$-induced growth arrest and tumour involution provides important information for further studies. As discussed by these authors, it will be important to determine the function of these $\mathrm{TH}$ responsive genes.

Targeted overexpression of $\mathrm{LH}$ in transgenic mice results in ovary-dependent pituitary adenoma, i.e. preceded by hyperproliferation of cells expressing the transcription factor Pit-1 (Mohammed et al. 2004a). To identify genes involved in pituitary tumorigenesis in this mouse model, Mohammed et al. (2004b). Undertook global genes expression profiling using Affymetrix GeneChips interrogating more than 12000 genes and expressed sequence tags (ESTs). A number of candidate genes were identified in tumour samples relative to wild-type littermates; 54 genes showing increased expression and 53 decreased. Of particular note, p8 (candidate of metastasis-1) was increased more than 12-fold in tumours relative to wild-type controls. Expression of p8, as determined by in situ hybridization, localized to tumour foci comprising lactotrophs suggesting a linkage with their oncogenic transformation. Further evidence, supporting a role of p8 in pituitary tumorigenesis, was obtained through antisense knockdown of $\mathrm{p} 8$ expression in GH3 (somatolactotroph lineage) and L 3 T2 (gonadotroph lineage) cells. Both cell lineages displayed attenuated tumour development or failed to grow when injected into athymic mice. These elegant studies suggest that $\mathrm{p} 8$ expression is required for maintaining a tumour phenotype. Importantly, these studies also suggest that $\mathrm{p} 8$ expression may represent only one of several distinct events in tumorigenesis. In this context, increased $\mathrm{p} 8$ expression was not found in hyperplastic tissue that precedes adenoma formation in this model. Increase expression of $\mathrm{p} 8$ is found in different human cancers and s.c. or i.p. injection of p8expressing fibroblasts, but not their null counterparts, leads to tumour formation in nude mice (Iovanna 2002). Furthermore, recent studies have suggested that increase expression of $\mathrm{p} 8$ plays an important part in disease progression of papillary and medullary thyroid carcinomas (Ito et al. 2003, 2005). No doubt, future studies will seek to identify the molecular target of $\mathrm{p} 8$ in a pituitary context and the role of $\mathrm{p} 8$ homologues in human pituitary tumours. 


\section{Concluding remarks}

The application of essentially unbiased global genome profiling towards a clearer understanding of the molecular aberrations that underlie pituitary tumorigenesis has yielded novel data and new insights. The techniques thus far employed vary in their complexity and also in their subsequent interpretation. In this context, it is perhaps microarray experiments, together with the accurate interpretation of the derived data sets, that present the most significant challenge. In these cases, as more data emerge, and as methodologies and analyses are further refined, then these type of studies will allow us to draw more reliable conclusions. Identification of the primary molecular aberration(s) responsible for the evolution of human pituitary adenomas has, thus far, eluded investigators. Identification, at least in part, has been frustrated by the absence in the majority of cases of a hyperplasia preceding tumour development. In this context, our own studies identified methylation of the p16 gene $\mathrm{CpG}$ island in apparent normal pituitaries and corticotroph hyperplasia associated with Cushing's disease (Simpson et al. 2004). Although these findings suggest that methylation of the p16 is an early change in pituitary tumourigenesis, they may simply reflect identification of tumour cells, albeit few in number, 'scattered' throughout the specimen. It is perhaps those animal models in which hyperplasia precedes adenoma formation that may prove informative with respect to the identification of bone fide initiating events. These models, combined with genome-wide scanning techniques, be they microarrays, proteomics, differential display or genome-wide methylation scans, may provide us with this new knowledge.

\section{Acknowledgements}

Research in the author's laboratory is supported by North Staffordshire Hospital Cancer Charity and the Samantha Dickson Research Trust/UK Brain Tumour Society. The author declares that there is no conflict of interest that would prejudice the impartiality of this scientific work.

\section{References}

Abbud RA, Takumi I, Barker EM, Ren SG, Vhen DY, Wawroswsky K \& Melmed S 2005 Early multipotential pituitary focal hyperplasia in the alpha-subunit of glycoprotein hormone-driven pituitary tumor-transforming gene transgenic mice. Molecular Endocrinology 19 1383-1391.
Alexander JM, Biller BMK, Bikkal H, Zervas NT, Arnold A \& Klibanski A 1990 Clinically non-functional pituitary tumors are monoclonal in origin. Journal of Clinical Investigation 86 336-340.

Asa SL \& Ezzat S 2002 The pathogenesis of pituitary tumors. Nature Reviews Cancer 2 836-849.

Asa SL \& Ezzat S 2005 Genetics and proteomics of pituitary tumors. Endocrine 28 43-47.

Bahar A, Bicknell JE, Simpson DJ, Clayton RN \& Farrell WE $2004 a$ Loss of expression of the growth inhibitory gene GADD45 $\gamma$, in human pituitary adenomas, is associated with $\mathrm{CpG}$ island methylation. Oncogene $\mathbf{2 3}$ 936-944.

Bahar A, Simpson DJ, Cutty SJ, Bicknell JE, Hoban PR, Holley S, Mourtada-Maarabouni M, Williams GT, Clayton RN \& Farrell WE 2004b Isolation and characterization of a novel pituitary tumor apoptosis gene. Molecular Endocrinolgy 18 1827-1839.

Bates AS, Farrell WE, Bicknell EJ, Talbot AJ, Broome JC, Perrett CW, Thakker RV \& Clayton RN 1997 Allelic deletion in pituitary adenomas reflects aggressive biological activity and has potential value as a prognostic marker. Journal of Clinical Endocrinology and Metabolism 82 818-824.

Buch HN, Raskauskiene D, Bahar A, Bicknell EJ, Farrell WE \& Clayton RN 2004 Prediction of recurrence of nonfunctioning pituitary tumours by loss of heterozygosity analysis. Clinical Endocrinology 61 19-25.

Chesnokova V, Castro A-V, Kovaks K \& Melmed S 2005 Pituitary hypolasia in $\mathrm{Pttg}^{-1-}$ mice is protective for $\mathrm{Rb}^{+/-}$ pituitary tumorigenesis. Molecular Endocrinology 19 2371-2379.

Daniely M, Aviram A, Adams EF, Buchfelder M, Barkkai G, Fahlbusch R, Goldman B \& Friedman E 1998 Comparative genomic hybridization analysis of nonfunctioning pituitary tumors. Journal of Clinical Endocrinology Metabolism 83 1801-1805.

Draghici S, Khatri P, Eklund AC \& Szallasi Z 2006 Reliability and reproducibility issues in DNA microarray measurements. Trends in Genetics 22 101-109.

Evans C-O, Young AN, Brown MR, Brat DJ, Parks JS, Neish AS \& Oyesiku NM 2001 Novel patterns of gene expression in pituitary adenomas identified by complementary deoxyribonucleic acid microarrays and quantitative reverse transcription-polymerase chain reaction. Journal of Clinical Endocrinology and Metabolism 86 3097-3107.

Fan X, Paetau A, Aalto Y, Valimaki M, Sane T, Poranen A, Castresana JS \& Knuutila S 2001 Gain of chromosome 3 and loss of $13 \mathrm{q}$ are frequent alterations in pituitary adenomas. Cancer Genetics and Cytogenetics $\mathbf{1 2 8}$ 97-103.

Farrell WE 2005 Epigenetic mechanisms of tumorigenesis. Hormones Metabolism Research 37 361-368.

Fathallah-Shaykh HM 2005 Microarrays applications and pitfalls. Archives of Neurology 62 1669-1672. 
Finelli P, Giardino D, Rizzi N, Buiatiotis S, Virduci T, Franzin A \& Losa-Larizza L 2000 Non-random trisomies of chromosome 5, 8 and 12 in prolactinomas sub-type of pituitary adenomas; conventional cytogenetic and interphase FISH study. International Journal of Cancer 86 344-350.

Frost SJ, Simpson DJ, Clayton RN \& Farrell WE 1999 Transfection of an inducible p16/CDKN2A construct mediated reversible growth inhibition and G1 arrest in the AtT20 pituitary tumor cell line. Molecular Endocrinology 13 1801-1810.

Giacomini D, Paez-Pereda M, Theodoropoulou M, Labeur M, Refojo D, Gerez J, Cherum A, Berner S, Losa M, Buch felder M et al. 2006 Bone morphogenetic protein-4: involvement in the retinoic acid inhibitory action. Endocrinology 147 247-256.

Goidin D, Kappeler L, Perrot J, Epelbaum J \& Gourdji D 2000 Differential pituitary gene expression profiles associated- to aging and spontaneous tumors as revealed by rat cDNA expression array. Endocrinology 141 4805-4808.

Gonzalgo ML, Liang G, Spruck CH, Zingg JM, Rideout WH \& Jones PA 1997 Identification and characterisation of differentially methylated regions of genomic DNA by methylation-sensitive arbitrarily primed PCR. Cancer Research 57 594-599.

Harada K, Nishizaki T, Ozaki S, Kubota H, Harada K, Okamura T, Ito H \& Sasaki K 1999 Cytogenetic alterations in pituitary adenomas detected by comparative genomic hybridization. Cancer Genetics and Cytogenetics 112 38-41.

Heaney AP \& Melmed S 2004 Molecular targets in pituitary tumours. Nature Reviews in Cancer 4 285-295.

Herman V, Fagin J, Gonsky R, Kovaks K \& Melmed S 1990 Clonal origin of pituitary adenomas. Journal of Clinical Endocrinology and Metabolism 71 1427-1433.

Horwitz GA, Miklovsky I, Heaney AP, Ren SG \& Melmed S 2003 Human pituitary transforming gene (PTTG1) motifs suppresses prolactin expression. Molecular Endocrinology 17 600-609.

Hui ABY, Pang JCS, Ko C-W \& Ng H-K 1999 Detection of chromosomal imbalances in growth hormone-secreting pituitary tumors by comparative genomic hybridisation. Human Pathology 30 1019-1023.

Hu YF, Kaplow J \& He Y 2005 From traditional biomarkers to transcriptome analysis in drug development. Current Molecular Medicine 5 29-38.

Iovanna JL 2002 Expression of the stress-associated protein p8 is a requisite for tumour development. International Journal of Gastrointestinal Cancer 31 89-98.

Ito Y, Yoshida H, Motoo Y, Miyoshi E, Iovanna JL, Tomoda C, Uruno T, Takamura Y, Miya A, Kobayashi K, Matsuzuku F, Matsuura N, Kuma K \& Miyauchi A 2003 Expression and cellular localization of $\mathrm{p} 8$ protein in thyroid neoplasms. Cancer Letters 201 237-244.

Ito Y, Yoshida H, Motoo Y, Iovanna JL, Tomoda C, Uruno T, Takamura Y, Miya A, Kobayashi K, Matsuzuku F,
Matsuzuka F, Kuma K \& Miyauchi A 2005 Expression of p8 protein in medullary thyroid carcinoma. Anticancer Research 25 3419-3423.

Jones PA \& Baylin SB 2002 The fundamental role of epigenetic events in cancer. Nature Reviews in Genetics 3 415-428.

Kovacs K \& Hovarth E 1987 Pathology of pituitary tumors. Endocrinology and Metabolism Clinics of North America 16 529-551.

Levy A \& Lightman S 2003 Molecular defects in the pathogenesis of pituitary tumours. Frontiers in Neuroendocrinology 24 94-127.

Melmed S 2003 Mechanisms of pituitary tumorigenesis: the plastic pituitary. Journal of Clinical Investigation 112 1603-1618.

Metzger AK, Mohapatra G, Minn YA, Bollen AW, Lamborn K, Waldman FM, Wilson CB \& Feuerstein BG 1999 Multiple genetic aberrations including evidence of chromosome 11q13 rearrangement detected in primary adenomas by comparative genomic hybridization. Journal of Neurosurgery 90 306-314.

Mohammed HP, Abbud RA, Parlow AF, Lewin JS \& Nilson JH $2004 a$ Targeted overexpression of luteinizing hormone causes ovary-dependent functional adenomas restricted to cells of the Pit-1 lineage. Endocrinology 144 4626-4636.

Mohammed HP, Seachrist DD, Quirk CC \& Nilson JH $2004 b$ Reexpression of $\mathrm{p} 8$ contributes to tumorigenic properties of pituitary cells and appears in a subset of prolactinomas in transgenic mice that hypersecrete luteinizing hormone. Molecular Endocrinology 18 2583-2593.

Moreno CS, Evans C-O, Zhan X, Okor M, Desiderion DM \& Oyesiku NM 2005 Novel molecular signaling and classification of human clinically non-functional pituitary adenomas identified by gene expression profiling and proteomic analysis. Cancer Research 65 10214-10222.

Morris DG, Musat M, Czirjak S, Hanzely Z, Lillington DM, Korbonits M \& Grossman AB 2005 Differential gene expression in pituitary adenomas by oligonucleotide array analysis. European Journal of Endocrinology 153 143-151.

Paez-Pereda M, Kovalovsky D, Hopfner U, Theodoropoulou M, Pagotto U, Uhl E, Losa M, Stalla J, Grubler Y, Missale C et al. 2001 Retinoic acid prevent experimental Cushing syndrome. Journal of Clinical Investigation 108 1123-1131.

Paez-Pereda M, Giacommini D, Refojo D, Nagashima AC, Hopfner U, Grubler Y, Chermin A, Goldberg V, Goya R Hentges ST et al. 2003 Involvement of bone morphogenetic protein 4 (BMP-4) in pituitary prolactinoma pathogenesis through a Smad/estrogen receptor crosstalk. PNAS 100 1034-1039.

Pei L \& Melmed S 1997 Isolation and characterization of pituitary tumor-transforming gene (PTTG). Molecular Endocrinology 11 433-441.

Pernicone PJ, Scheithauer B, Sebo TJ, Kovaks KT, Hovath E, Young WF, Jr, Lloyd RV, Davis DH, Guthrie BH \& Schoene WC 1997 Pituitary carcinoma: a clinicopathologic study of 15 cases. Cancer 79 804-812. 
Rickert CH, Busch BD-DG, Moskopp D, Albert FK, Rama B \& Paulus W 2001 Increased chromosomal imbalance in recurrent pituitary adenomas. Acta Neuropathologica 102 615-620.

Simpson DJ, McNicol dAM, Murray DC, Bahar A, Turner HE, Wass JAH, Esiri MM, Clayton RN \& Farrell WE 2004 Molecular pathology shows p16 methylation in nonadenomatous pituitaries from patients with Cushing's disease. Clinical Cancer Research 10 1780-1788.

Tanaka C, Yoshimoto K, Yang P, Kimura T, Yamada S, Moritani M, Sano T \& Itakura M 1997 Infrequent mutations of $\mathrm{p} 27^{\mathrm{Kip} 1}$ gene and trisomy 12 in a subset of human pituitary adenomas. Journal of Clinical Endocrinology and Metabolism 82 3141-3147.

Trautmann K, Thakker RV, Ellison DW, Ibrahim A, Lees PD, Harding B, Fischer C, Popp S, Bartmram CR \& Jauch A 2001 Chromosomal aberrations in sporadic pituitary tumors. International Journal of Cancer 91 809-814.

Wood WM, Sapapura VD, Dowding JM, Woodmansee WM, Haakinson DJ, Gordon DF \& Ridgway EC 2002 Early gene expression changes preceding thyroid hormone-induced involution of a thyrotrope tumor. Endocrinology 143 347-359.
Yin D, Kondo S, Takeuchi J, Morimura T \& Vaux DL 1994 Bcl-2 gene prevents apoptosis in murine ACTH-secreting adenoma cells induced by bromocriptine. International Journal of Oncology 4 187-191.

Yin D, Tamaki N, Kokunai T, Yasuo K \& Yonezawa K 1999 Bromocriptine-induced apoptosis in pituitary adenoma cells: relationship to $\mathrm{p} 53$ and bcl-2 expression. Journal of Clinical Neuroscience 6 326-331.

Zhang X, Howitz GA, Heaney AP, Nakashima M, Prezant TR, Bronstein MD \& Melmed S 1999 Pituitary tumor transforming gene (PTTG) expression in pituitary adenomas. Journal of Clinical Endocrinology and Metabolism 84 761-767.

Zhang X, Sun H, Danila DC, Johnson SR, Zhou Y, Swearingen B \& Klibanski A 2002 Loss of expression of GADD45 $\gamma$, a growth inhibitory gene, in human pituitary adenomas: implications for tumorigenesis. Journal of Clinical Endocrinology and Metabolism 87 1262-1267.

Zhao J, Dahle D, Zhou Y, Zhang X \& Klibanski A 2005 Hypermethylation of the promoter region is associated with the loss of $M E G 3$ gene expression in human pituitary tumors. Journal of Clinical Endocrinology and Metabolism 90 2179-2186. 